\title{
Influence of the Expandable Graphite on the Thermal properties of a Rigid Polyurethane Foam for construction
}

\author{
Lenar Shafigullin ${ }^{1 *}$, Natalya Romanova ${ }^{1}$, Gulnaz Shafigullina ${ }^{1}$, and Yulia Sokolova ${ }^{2}$ \\ ${ }^{1}$ Kazan Federal University, Naberezhnye Chelny Institute, 423810 Naberezhnye Chelny, Russia \\ ${ }^{2}$ Moscow State University of Civil Engineering, Yaroslavskoe shosse, 26, Moscow, 129337, Russia
}

\begin{abstract}
In this paper, low-combustible composites were made by adding $0.8-25 \mathrm{wt} \%$ of expandable graphite to rigid polyurethane foams (PUF) to ensure effective and safe usage of building materials made of PUFs. Thermal gravimetric analysis (TGA) was used to study thermal properties and effectiveness of the resulting low-combustible composites in construction. The analysis of TGA curves of the studied composites can be interpreted as a two-stage process: acid-catalyzed degradation of PUF and formation of an intumescent char layer. A dense intumescent layer can provide an effective prevention of heat transfer. The paper showed that the addition of $25 \mathrm{wt} \%$ of expandable graphite to PUF composite improved the thermal stability by $8{ }^{\circ} \mathrm{C}$, as compared to starting PUF, while the residue was $36.2 \mathrm{wt} \%$ at $600^{\circ} \mathrm{C}$, which was higher by approximately $16 \mathrm{wt} \%$ than the residue of starting PUF. So, the sample with $25 \%$ loading of expandable graphite in rigid PUF composite showed the best thermal characteristics.
\end{abstract}

\section{Introduction}

Nowadays, polyurethanes have been widely applied in paints, adhesives, elastomers, flexible and rigid foams, etc, and thus play an increasing important role in industry and daily life [1-3]. In the last thirty years, concerns about energy conservation have led to a worldwide use of thermal insulators. In particular rigid polyurethane foams (PUF) have been widely used for insulation in construction due to their superior mechanical properties and low thermal conductivity [4].

Rigid PUFs are usually made from branched hydroxyl terminated polyols and multifunctional isocyanates like methylene diphenyl diisocyanate (MDI) [5]. Foamed materials have a density within the range of from 16 to $48 \mathrm{~kg} / \mathrm{m}^{3}$ and feature high mechanical strength for this density range [6], which is advantageous for construction applications.

The behavior of building materials during burning is the deciding factor that determines their safety. Like all organic materials, rigid PUFs degrade and burn when exposed to

* Corresponding author: misharin_82@mail.ru 
flame. Rigid PUFs are classified as combustible materials with medium flammability, which inhibits their wide application in construction. Meanwhile, the increasingly stringent requirements for fire safety of materials, especially those used in construction, have led to the approval of new regulations and wide applications of flame retarded materials [7-9].

The most common fireproofing method for PUFs is the incorporation of flame retardants during their production. The most common flame retardants are phosphohalogenated compounds.

Polymer materials containing conventional flame retardants generate highly toxic compounds during burning. For these reasons, there is a demand for materials which feature lower combustibility and low toxicity of combustion products. Intumescent compounds are promising materials to address those challenges.

Intumescent compounds are well known as new generation of flame retardants due to their merits, such as low emission of smoke and toxic gases produced during burning and anti-dripping properties [6]. Such an effective flame retardant is expandable graphite (EG).

EG is known to provide an effective protection for polymers. The layer structure of graphite makes it possible to insert other molecules between layers, for example, sulfuric or nitric acid. When subjected to heat, these inserted molecules degrade with the evolution of gas, the foaming occurs, and the layer thickness increases by 100 times. Typically, EG is used in combination with phosphorus compounds, antimony oxides, or metal hydroxides, which act as a substrate for the layer of expanded graphite [10-15].

Therefore, the relevant objective is to make low-combustible compositions by adding expandable graphite, as well as to study thermal properties of the resulting compositions to evaluate their combustibility in order to ensure effective and safe usage of building materials made of PUFs.

\section{Materials and Methods}

The main components of urethane mixture were polyol A (Izolan A 210-7) [16], isocyanate B (Voratec SD 100) [16], expandable graphite (METOPAC EG 350-50 (80), GK Khimicheskie Systemy) [17]. The components were mixed manually in the following order: the expandable graphite was added to polyol A and mixed thoroughly for 5 minutes; isocyanate $\mathrm{B}$ was added to this mixture and mixed till the reaction of interaction started; the resulting mixture was poured into the pre-heated molding tool, the molding sides were closed, and it was held for 6 minutes. The samples were conditioned at the room temperature for 24 hours.

Table 1 shows the composition of the rigid PUF samples without and with expandable graphite.

Table 1. Composition of PUF samples.

\begin{tabular}{|l|c|c|c|}
\hline Sample name & $\begin{array}{l}\text { Polyol (weight } \\
\text { parts) }\end{array}$ & $\begin{array}{l}\text { Isocyanate (weight } \\
\text { parts) }\end{array}$ & EG (weight parts) \\
\hline RPUF & 100 & 55 & 0 \\
\hline RPUF/EG0.8 & 100 & 55 & 0.5 \\
\hline RPUF/EG4 & 100 & 55 & 2.5 \\
\hline RPUF/EG8 & 100 & 55 & 5.0 \\
\hline RPUF/EG16 & 100 & 55 & 10.0 \\
\hline RPUF/EG25 & 100 & 55 & 15.0 \\
\hline
\end{tabular}

The resulting samples were studied to determine the following parameters: 
1. The thermal conductivity $(\lambda)$ was determined by the procedure according to GOST 7076-99 [18]. The test equipment was the electronic thermal conductivity meter ITP-MG4.

2. The thermal gravimetric analysis was recorded using synchronous thermal analyzer TG $209 \mathrm{~F} 1$ [19]. For thermal degradation, the samples were heated from $30{ }^{\circ} \mathrm{C}$ to $600{ }^{\circ} \mathrm{C}$ at a rate of $10^{\circ} \mathrm{C} / \mathrm{min}$ in argon or air atmosphere according to GOST 29127 [20].

\section{Results and discussion}

A widespread use of rigid PUFs for thermal insulation in construction is driven by their low thermal conductivity. It is known that radiation, convection within the cells, and conduction through the polymer network are involved in heat transfer through PUF. In view of this, thermal conductivity is a function of not only gas composition, but also foam density and structure [6].

The results of thermal conductivity calculation are given in Table 2 .

Table 2. Thermal conductivity of PUFs.

\begin{tabular}{|l|l|l|l|l|l|l|}
\hline Parameter & RPUF & $\begin{array}{l}\text { RPUF/ } \\
\text { EG0.8 }\end{array}$ & $\begin{array}{l}\text { RPUF/ } \\
\text { EG4 }\end{array}$ & $\begin{array}{l}\text { RPUF/ } \\
\text { EG8 }\end{array}$ & $\begin{array}{l}\text { RPUF/ } \\
\text { EG16 }\end{array}$ & $\begin{array}{l}\text { RPUF/ } \\
\text { EG25 }\end{array}$ \\
\hline$\lambda(\mathrm{W} /(\mathrm{m} * \mathrm{~K}))$ & 0.061 & 0.062 & 0.066 & 0.055 & 0.058 & 0.056 \\
\hline
\end{tabular}

Low thermal conductivity of RPUF sample $\left(\lambda=0.061 \mathrm{~W} /\left(\mathrm{m}^{*} \mathrm{~K}\right)\right)$ is the reason why the temperature of its surface increases quickly when ignition occurs, which leads to a rapid flame propagation on the surface.

In this paper, expandable graphite was added to the formulation to slow down surface burning, which had an insignificant influence on the thermal conductivity of PUF. Thus, $\lambda$ $=0.056 \mathrm{~W} /\left(\mathrm{m}^{*} \mathrm{~K}\right.$ ) with $25 \mathrm{wt} \%$ in PUF (sample RPUF/EG25). So, the addition of max. 4 $\mathrm{wt} \%$ of EG to PUF has no impact on thermal conductivity, and $8-25 \mathrm{wt} \%$ of EG in PUF results in an insignificant decrease in this property as compared to the starting PUF.

Therefore, thermal conductivity of PUF composite with various EG loadings does not depend on their content as thermal conductivity is based on the void content in the material.

The burning behavior of a material depends on the ease of its thermal degradation. Thermal analysis provides sufficient information about the mechanism of material degradation, chemical transformations and other processes, which are followed by mass loss, endothermic and exothermic reactions. This method makes it possible to analyze thermal degradation of PUFs using the obtained data.

Thermal stability of PUF samples, including the starting sample and EG-filled samples, was studied using TGA in argon and air atmosphere.

Figure 1 shows the investigation of degradation process in the inert atmosphere (TGA curves), and Figure 2 shows DTG curves.

The thermograms of the studied PUF samples (Figures 1,2) were used to determine the onset temperatures, temperatures at $5 \%$ mass loss $\left(\mathrm{T}_{5 \%}\right)$, the temperatures of maximum degradation rate $\left(\mathrm{T}_{\max }\right)$, residue char at $600{ }^{\circ} \mathrm{C}$, maximum degradation rate at $\mathrm{T}_{\max }$, these parameters were summarized in Table 3.

TGA analysis in the inert atmosphere (Table 3, Figures 1,2) showed that all the samples went through several stages of mass loss with various intensity. So, the degradation of the starting PUF sample had four stages.

Table 3. Data obtained from curves of TGA tests of RPUF and RPUF/EG composites under argon.

\begin{tabular}{|l|l|l|l|l|l|l|}
\hline Samples & $\begin{array}{l}\mathrm{T}_{5 \%} \\
\left({ }^{\circ} \mathrm{C}\right)\end{array}$ & $\mathrm{T}_{\max 1}\left({ }^{\circ} \mathrm{C}\right)$ & $\begin{array}{l}\text { Mass loss } \\
\text { rate at } \mathrm{T}_{\max 1} \\
(\mathrm{wt} \% / \mathrm{min})\end{array}$ & $\begin{array}{l}\mathrm{T}_{\max 2} \\
\left({ }^{\circ} \mathrm{C}\right)\end{array}$ & $\begin{array}{l}\text { Mass loss } \\
\text { rate at } \mathrm{T}_{\max 2} \\
(\mathrm{wt} \% / \mathrm{min})\end{array}$ & $\begin{array}{l}\text { Char } \\
\text { residue } \\
(\%)\end{array}$ \\
\hline
\end{tabular}




\begin{tabular}{|l|c|c|c|c|c|c|}
\hline RPUF & 247 & 329 & 6.5 & 361 & 5.9 & 20.3 \\
\hline RPUF/EG0.8 & 240 & 334 & 5.3 & 367 & 5.4 & 20.7 \\
\hline RPUF/EG4 & 254 & 324 & 5.8 & 373 & 5.1 & 23.8 \\
\hline RPUF/EG8 & 214 & 308 & 6.5 & - & - & 26.4 \\
\hline RPUF/EG16 & 188 & 310 & 6.9 & - & - & 28.4 \\
\hline RPUF/EG25 & 255 & 321 & 6.2 & - & - & 36.2 \\
\hline
\end{tabular}

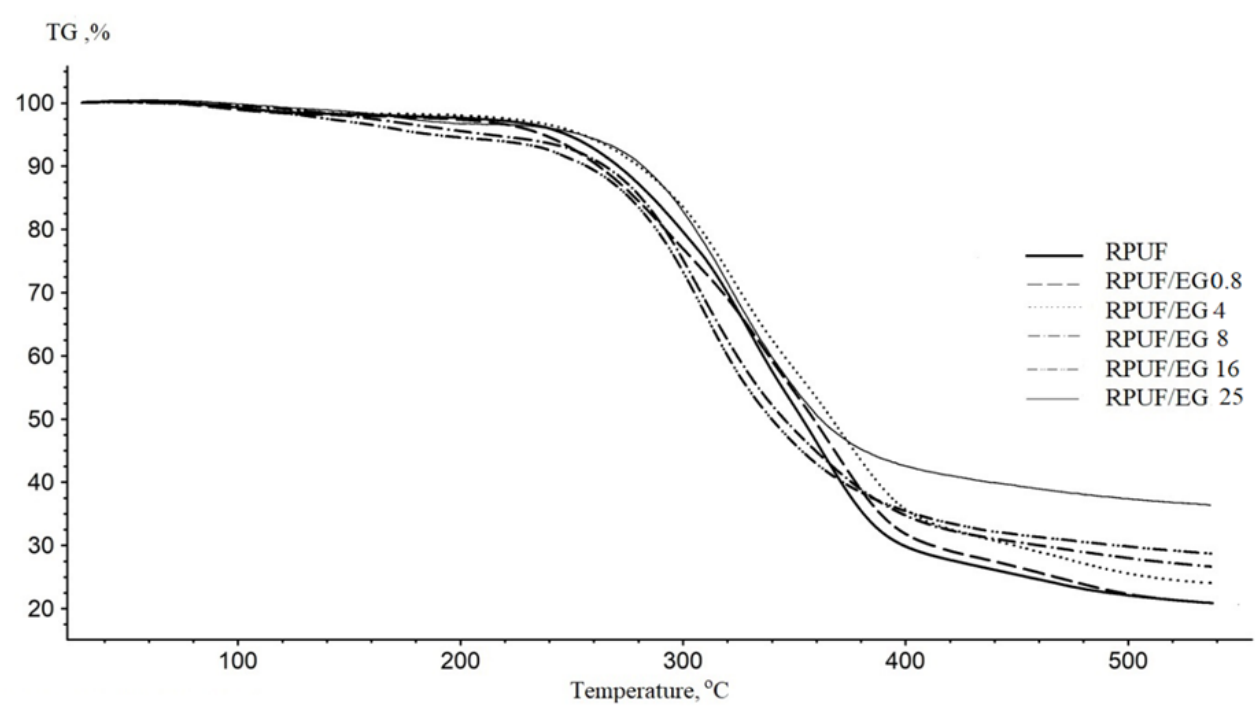

Fig. 1. TGA curves of RPUF and RPUF/EG composites under argon.

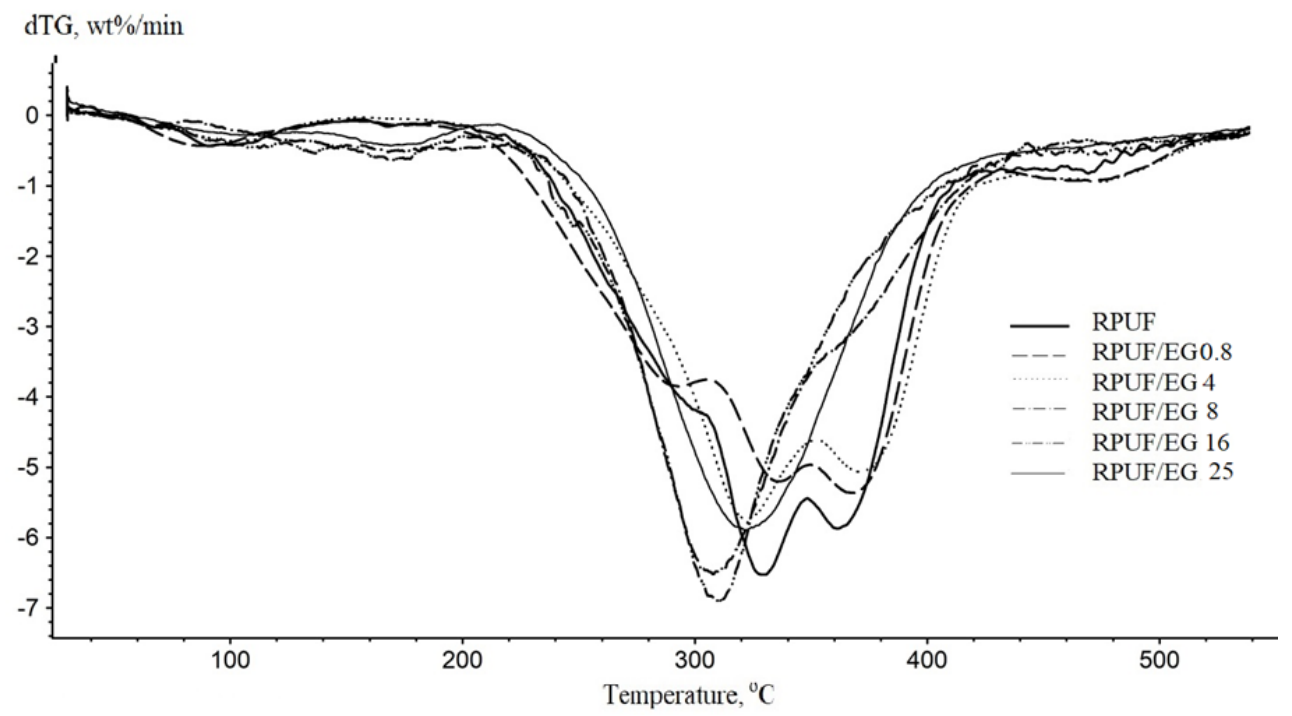

Fig. 2. DTG curves of RPUF and RPUF/EG composites under argon.

Only the samples with graphite loading of up to $4 \mathrm{wt} \%$ (samples RPUF/EG0.8, RPUF/EG4) has TG and DTG curves (Figures 1,2) of the nature similar to starting PUF. 
The first degradation stage of starting PUF and samples with a loading of $0.8 \mathrm{wt} \%$ (RPUF/EG0.8) and $4 \mathrm{wt} \%$ (RPUF/EG4) features a region between $70{ }^{\circ} \mathrm{C}$ and $200{ }^{\circ} \mathrm{C}$ with $2.5 \%$ mass loss. This stage can be associated with evaporation of small molecules of unreacted isocyanate starting components [21]. The second and third degradation stages occur at temperatures of $210-340{ }^{\circ} \mathrm{C}$ and $350-450{ }^{\circ} \mathrm{C}$ respectively, and it is primarily due to the formation of starting polyurethane components (isocyanates and polyols) as a result of breaking of urethane bonds in hard segments [21]. Hence, PUF has a bimodal structure and features two peak degradation temperatures $\mathrm{T}_{\max 1}$ and $\mathrm{T}_{\max 2}$ (Figure 2, Table 3). The first and second peak degradation temperatures correspond to the hard and soft segments of polyurethane, respectively. The material degradation ends at a temperature of above 450 ${ }^{\circ} \mathrm{C}$.

The analysis of TG curves (Figure 1) showed that the thermal stability of RPUF/EG4 sample with $4 \mathrm{wt} \%$ loading increased by $7{ }^{\circ} \mathrm{C}$ as compared to the starting PUF $\left(\mathrm{T}_{5 \%}=247\right.$ ${ }^{\circ} \mathrm{C}$ ), and $\mathrm{T}_{5 \%}$ is $254{ }^{\circ} \mathrm{C}$.

The mass loss rate decreases depending on the graphite loading (Table 3). The reason is that the intumescent layer forms at the initial degradation stage, and the volatile combustible fragments could have diffused slowly as a result of thermal degradation, so the mass loss rate decreased. At the same time, the content of residue also increases with increasing loading of graphite at $600{ }^{\circ} \mathrm{C}$ : from $20.3 \mathrm{wt} \%$ for starting PUF to $23.8 \mathrm{wt} \%$ for RPUF/EG4 sample with $4 \%$ loading, which indicates that the char layer has formed.

Therefore, as the amount of graphite increases up to $4 \mathrm{wt} \%$ in PUF composite denser intumescent particles form, which results in lower mass loss rate and higher thermal stability.

The studied PUF samples with $8-25 \mathrm{wt} \%$ of graphite loading go through three degradation stages (Figure 2). RPUF/EG8, RPUF/EG16, RPUF/EG25 samples show the following stages:

$-70-200{ }^{\circ} \mathrm{C}$ : removal of highly volatile components and unreacted starting components;

$-210-450{ }^{\circ} \mathrm{C}$ : activation of thermal oxidative processes and resolution of polyurethane into starting products (isocyanate and polyatomic alcohol), which is followed by significant heat production;

$->450{ }^{\circ} \mathrm{C}$ : completion of the material degradation.

PUF composites with 8 and $16 \%$ of graphite loading have lower temperature characteristics as compared to the starting PUF. Residual acid inside the EG layers can contribute to lower degradation temperatures of PUF polymer matrix [22]. For example, onset temperature of $\mathrm{T}_{5 \%}=214{ }^{\circ} \mathrm{C}$ and $\mathrm{T}_{\max }=308{ }^{\circ} \mathrm{C}$ is typical for the sample with $8 \%$ loading of graphite (RPUF/EG8 sample, Table 3), and $\mathrm{T}_{5 \%}=188^{\circ} \mathrm{C}, \mathrm{T}_{\max }=310{ }^{\circ} \mathrm{C}$ - for the sample with $16 \%$ loading of graphite (RPUF/EG16, Table 3), and the residue is $26.4 \mathrm{wt} \%$ and $28.4 \mathrm{wt} \%$, respectively, at $600{ }^{\circ} \mathrm{C}$, this value exceeds the value of starting PUF material by $6.1 \mathrm{wt} \%$ and $8.1 \mathrm{wt} \%$, respectively.

Therefore, 8 and $16 \mathrm{wt} \%$ of EG in PUF composite accelerated the initial degradation stage significantly. It resulted in the formation of a dense intumescent layer on the sample surface, which led to a slower degradation process in PUF and slow diffusion of volatile combustible fragments.

A higher amount of EG in PUF composite ( $25 \mathrm{wt} \%)$ improves the thermal stability by 8 ${ }^{\circ} \mathrm{C}$, as compared to starting PUF, and RPUF/EG25 sample features $\mathrm{T}_{5 \%}=255^{\circ} \mathrm{C}, \mathrm{T}_{\max }=321$ ${ }^{\circ} \mathrm{C}$, while the residue is $36.2 \mathrm{wt} \%$ at $600{ }^{\circ} \mathrm{C}$. Higher temperature characteristics of the initial degradation stage can be attributed to a higher expansion rate of graphite, i.e., a high EG loading $(25 \mathrm{wt} \%)$ of PUF results in larger particles of the intumescent layer in the composite, which slows down the degradation process of polymer matrix after acid decomposition. 
With a higher graphite loading, the char residue increases at $600{ }^{\circ} \mathrm{C}$ and peaks at 36.2 $\mathrm{wt} \%$ for RPUF/EG25 sample, the resulting intumescent layer acts as a heat insulation barrier to prevent PUF from further degradation.

Therefore, the thermal studies of PUF composites showed that EG loading of 0.8-25 $\mathrm{wt} \%$ led to the formation of an intumescent layer during heating for all the samples, and RPUF/EG25 sample with $25 \%$ loading had the best thermal characteristics, its char residue was $36.2 \mathrm{wt} \%$ at $600{ }^{\circ} \mathrm{C}$.

The thermal studies in air showed that the introduction of $0.8 \mathrm{wt} \%$ of EG did not change the main PUF degradation characteristics.

Figure 3 shows the investigation of the degradation process for the filled PUF samples under oxidizing atmosphere (TGA curves), and Figure 4 shows DTG curves. The analysis results for thermograms are shown in Table 4.

The addition of $4 \mathrm{wt} \%$ of EG to PUF composite results in higher thermal stability under oxidizing atmosphere, such parameters as $\mathrm{T}_{5 \%}$ and $\mathrm{T}_{\max }$ increase. For example, $\mathrm{T}_{5 \%}$ increases by $16{ }^{\circ} \mathrm{C}$ and is equal to $238{ }^{\circ} \mathrm{C}$, and $\mathrm{T}_{\max }=306{ }^{\circ} \mathrm{C}$, while the mass loss rate decreases down to $8.5 \mathrm{wt} \% / \mathrm{min}$.

The addition of $8 \mathrm{wt} \%$ of graphite to PUF leads to a significant decrease in such parameters as $\mathrm{T}_{5 \%}$ (approximately by $70{ }^{\circ} \mathrm{C}$ ) and $\mathrm{T}_{\max }$ (approximately by $8{ }^{\circ} \mathrm{C}$ ), the mass loss rate at $\mathrm{T}_{\max }$ also decreases from 10.7 to $7.9 \mathrm{wt} \% / \mathrm{min}$. Lower values of $\mathrm{T}_{5 \%}$ and $\mathrm{T}_{\max }$ were attributed to the influence of residual acid inside the EG layers, which accelerated the degradation in PUF.

EG loading of minimum $25 \mathrm{wt} \%$ is most effective for PUF composite. $\mathrm{T}_{5 \%}, \mathrm{~T}_{\max }$ are insignificantly lower in RPUF/EG25 sample than those in starting PUF, the mass loss rate at $\mathrm{T}_{\max }$ is lowest $(7.3 \mathrm{wt} \% / \mathrm{min})$ and the char amount is highest among all the other studied samples. So, the earlier degradation encouraged the formation of stable substances which inhibited the degradation rate and increased the char yield in the range of higher temperatures. So, the addition of EG of minimum $25 \mathrm{wt} \%$ to PUF leads to lower combustibility of the composite.

Table 4. Data obtained from curves of TGA tests of RPUF/EG composites under air.

\begin{tabular}{|l|c|c|c|}
\hline Samples & $\mathrm{T}_{5 \%}\left({ }^{\circ} \mathrm{C}\right)$ & $\mathrm{T}_{\max }\left({ }^{\circ} \mathrm{C}\right)$ & Mass loss rate at $\mathrm{T}_{\max }(\mathrm{wt} \% / \mathrm{min})$ \\
\hline RPUF & 222 & 302 & 10.7 \\
\hline RPUF/EG0.8 & 223 & 302 & 10.2 \\
\hline RPUF/EG4 & 238 & 306 & 8.5 \\
\hline RPUF/EG8 & 150 & 294 & 7.9 \\
\hline RPUF/EG25 & 218 & 300 & 7.3 \\
\hline
\end{tabular}




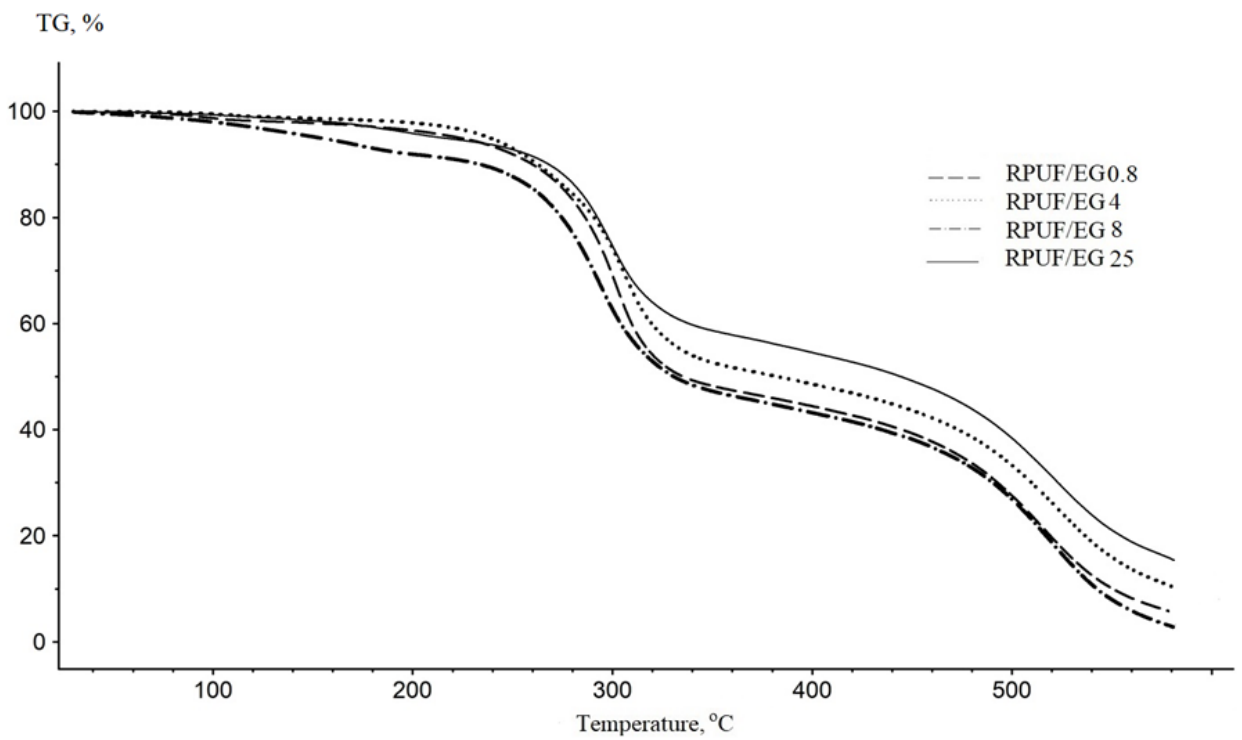

Fig. 3. GA curves of RPUF/EG composites under air.

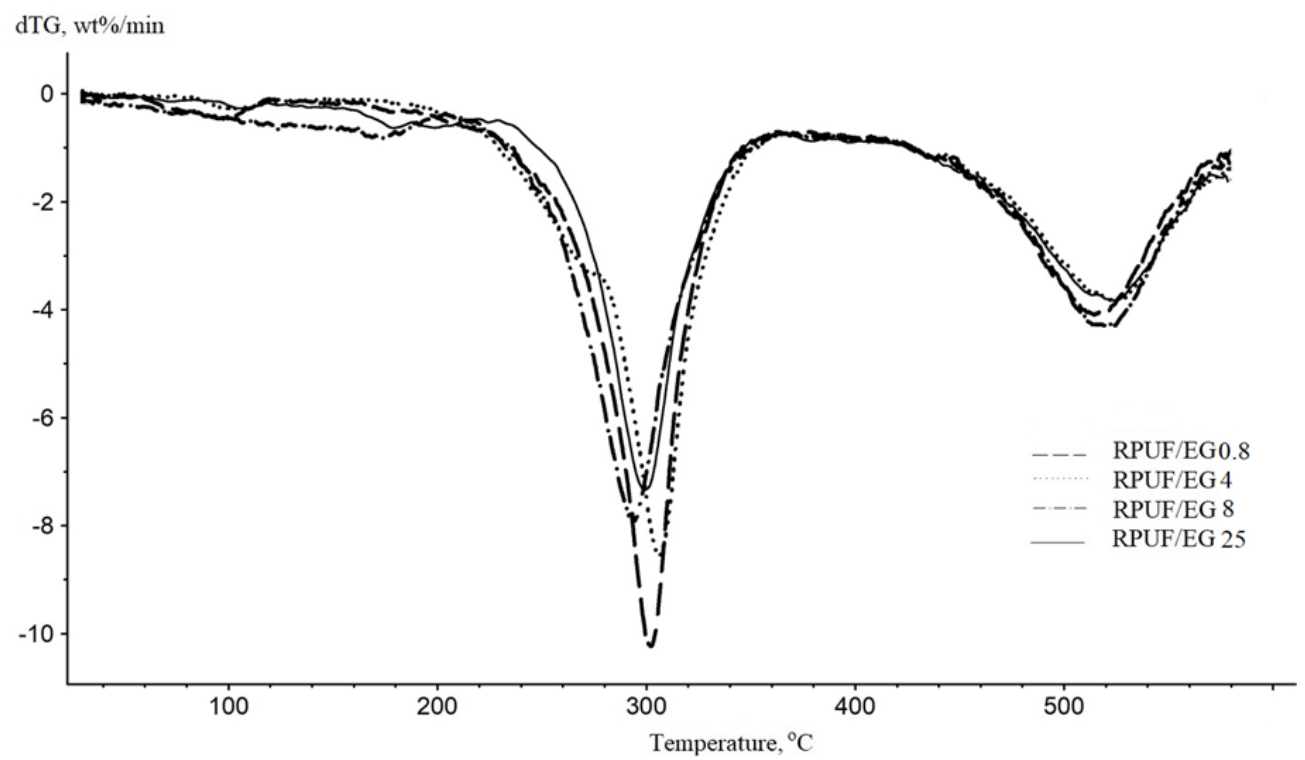

Fig. 4. DTG curves of RPUF/EG composites under air.

\section{Conclusions}

The thermal studies of PUF composites showed that EG loading of 4-25 wt\% led to the formation of an intumescent layer during heating for all the samples. RPUF/EG25 sample with $25 \%$ loading showed the best thermal characteristics. The addition of $25 \mathrm{wt} \%$ of EG to PUF composite improves the thermal stability by $8{ }^{\circ} \mathrm{C}$, as compared to starting PUF, and RPUF/EG25 sample features $\mathrm{T}_{5 \%}=255{ }^{\circ} \mathrm{C}, \mathrm{T}_{\max }=321{ }^{\circ} \mathrm{C}$, while the residue is $36.2 \mathrm{wt} \%$ at $600{ }^{\circ} \mathrm{C}$, which is $16 \mathrm{wt} \%$ higher that in starting PUF. Higher temperature characteristics of 
the initial degradation stage can be attributed to a higher expansion rate of graphite, i.e., a high EG loading ( $25 \mathrm{wt} \%$ ) of PUF results in larger particles of the intumescent layer in the composite, which slows down the degradation process of polymer matrix after acid decomposition.

When 8 and 16 wt $\%$ of EG were added in PUF, the composites accelerated the initial degradation stage significantly. It resulted in the formation of a dense intumescent layer on the sample surface, which led to a slower degradation process in PUF and slow diffusion of volatile combustible fragments. For example, onset temperature of $\mathrm{T}_{5 \%}=214{ }^{\circ} \mathrm{C}$ and $\mathrm{T}_{\max }=308{ }^{\circ} \mathrm{C}$ is typical for the sample with $8 \%$ loading of graphite, and $\mathrm{T}_{5 \%}=188{ }^{\circ} \mathrm{C}$, $\mathrm{T}_{\max }=310{ }^{\circ} \mathrm{C}$ - for the sample with $16 \%$ loading of graphite, and the residue is $26.4 \mathrm{wt} \%$ and $28.4 \mathrm{wt} \%$, respectively, at $600{ }^{\circ} \mathrm{C}$, this value exceeds the value of starting PUF material by $6.1 \mathrm{wt} \%$ and $8.1 \mathrm{wt} \%$, respectively.

\section{References}

1. J.H. Saunders, K.C. Frisch, Chemistry of Polyurethanes (Khimiya Publ., Moscow, 1968)

2. J.M Buist, Eur. Polyurethane Composites (Khimiya Publ., Moscow, 1982)

3. L. Shi, Z.-M. Li, M.-B. Yang, B. Yin; Q.-M. Zhou, C.-R. Tian, J.-H. Wang Expandable Graphite for Halogen-Free Flame-Retardant of High-Density Rigid Polyurethane Foams, J. Polym. Plast. Technol. Eng., 44, 1323-1327 (2005)

4. Jing Jina, Quan-xiao Dongb, Zhong-jun Shua, Wan-jin Wangb, Kui Heb Flame retardant Properties of Polyurethane/expandable Praphite Composites, Procedia Engineering, 71, $304-309$ ( 2014 )

5. E M. Gottlieb, E R. Galimov, L.A. Zenitova and others Polyurethanes: synthesis, properties and application in mechanical engineering (Kazan publishing house UN-TA, Kazan, 2016)

6. D. Klempner, Polymeric Foams and foam technology (Professiya Publ., Saint Petersburg, 2009)

7. A.A. Zakharchenko, M.A. Vaniev, A.B. Kochnov, D.V. Shokova, K.A. Emelyanenkova, I.A. Novakov The current state of the research in the sphere of lowflammable polyurethane foams production, Izvestia of Volgrograd Technical State University, 228, 7-18 (2019)

8. UNECE Regulation No. 118. Uniform technical prescriptions concerning the burning behaviour and/or the capability to repel fuel or lubricant of materials used in the construction of certain categories of motor vehicles: UNECE Regulation No. 118 of April 6, 2004. Information on http://docs.cntd.ru/document/ 1200106694.

9. Federal law No 123-FZ of July 22, 2008 "Technical regulations for fire safety requirements" (as amended). Information on https://base.garant.ru/ 12161584/

10. Yu.A. Mikhaylin, Heat, thermal and fire resistance of polymer materials (Nauchnye Osnovy I Tekhnologii Publ., Saint Petersburg, 2011)

11. Weiguo Yao, Dongyang Zhang, Yixin Zhang, Tao Fu, Dongbo Guan, Yanli Dou Synergistic Flame Retardant Effects of Expandable Graphite and Ammonium Polyphosphate in Water-Blow Polyurethane Foam, Advances in Materials Science and Engineering, Volume 2019, Article ID 6921474, 8 page https://doi.org/10.1155/2019/692147

12. Ting-Ting Li, Mengfan Xing, Hongyang Wang, Shih-Yu Huang, Chengeng Fu, ChingWen Lou, Jia-Horng Lin Nitrogen/phosphorus synergistic flame retardantfilled flexible 
polyurethane foams: microstructure, compressive stress, sound absorption, and combustion resistance, RSC Adv., 9, 21192-21201 (2019)

13. Wang Xi, Lijun Qian*, Zhigang Huang, Yanfang Cao, Linjie Li Continuous flameretardant actions of two phosphate esters with expandable graphite in rigid polyurethane foams, Polymer Degradation and Stability, 130, 97-102 (2016)

14. Bin Zhao, Dong-Yue Liu, Wen-Jun Liang, Fei La, Jun-Sheng Wang, Ya-Qing Liu Biphase flame-retardant actions of water-blown rigid polyurethanefoam containing diethyl-N,N-bis(2-hydroxyethyl) phosphoramide andexpandable graphite, Journal of Analytical and Applied Pyrolysis, 124, 247-255 (2017)

15. Wang Xi, Lijun Qian, Yajun Chen, Jingyu Wang, Xinxin Liu Addition flame-retardant behaviors of expandable graphite and [bis(2-hydroxyethyl)amino]-methyl-phosphonic acid dimethyl ester in rigid polyurethane foams, Polymer Degradation and Stability, 122, 36-43 (2015)

16. Information on http://www.dow-izolan.com/ru/production/construction/sandwichpanels-for-buildings-face-finishing

17. Information on http://chemsystem.ru/ catalog/41

18. GOST 7076-99 2000 Bullding materials and products. Method of determination of steady-state thermal conductivity and thermal resistance (Moscow, Gosstroy Rossii Publ., GUP TsPP)

19. Information on https://www.netzsch-thermal-analysis.com/ru/produktyreshenija/termogravimetricheskii-analiz/tg-209-f1-libra/

20. GOST R 29127-91 (ISO 7111-87) 1991 Plastics. Thermogravity of polymers (Moscow, Standartinform Publ.)

21. G. Camino, S. Duquesne, R. Delobel, B. Eling, C. Lindsay, T. Roels Mechanism of Expandable Graphite Fire Retardant Action in Polyurethanes, ACS Symposium Series, 797, Volume 8, 90 - 109 (2001) DOI: 10.1021/bk-2001-0797.ch008

22. Pablo Acuña, Zhi Li, Mercedes Santiago-Calvo, Fernando Villafañe, Miguel Ángel Rodríguez-Perez, De-Yi Wang Influence of the Characteristics of Expandable Graphite on the Morphology, Thermal Properties, Fire Behaviour and Compression Performance of a Rigid Polyurethane Foam/Polymers, 11, 168 (2019) 